\title{
Effects of continuous cropping of sugar beet (Beta vulgaris L.) on its endophytic and soil bacterial community by high- throughput sequencing
}

Miao Li, Fuzhen Yang, Xianyu Wu, Hai Yan ${ }^{*}$ and Yang Liu*

\begin{abstract}
Purpose: As a major sugar crop, sugar beet (Beta vulgaris L.) plays an important role in both sugar industry and feed products. Soil, acts as the substrate for plant growth, provides not only nutrients to plants but also a habitat for soil microorganisms. High soil fertility and good micro-ecological environment are basic requirements for obtaining high-yield and high-sugar sugar beets. This study aimed at exploring the effects of continuous cropping of sugar beet on its endophytic, soil bacterial community structures, and diversity.

Methods: Using high-throughput sequencing technology which is based on Illumina Hiseq 2500 platform, the seeds of sugar beet (sample S), non-continuous cropping sugar beet (sample Bn) with its rhizosphere soil (sample $\mathrm{Sr}$ ), and planting soil (sample Sn), continuous cropping sugar beet (sample Bc) with its planting soil (sample Sc), were collected as research materials.

Result: The results showed that the bacterial communities and diversity in each sample exhibited different OTU richness; $67.9 \%$ and $63.8 \%$ of total endophytic OTUs from samples BC and Bn shared with their planting soil samples Sc and Sn, while sharing $36.4 \%$ and $31.8 \%$ of total OTUs with their seed sample S. Pseudarthrobacter and Bacillus as the two major groups coexisted among all samples, and other shared groups belonged to Achromobacter, Sphingomonas, Novosphingobium, Terribacillus, Planococcus, Paracoccus, Nesterenkonia, Halomonas, and Nocardioides. Genera, including Pantoea, Pseudomonas, Stenotrophomonas, Weissella, Leuconostoc, and Acinetobacter, were detected in each sugar beet sample but not in their corresponding soil sample. In this study, the bacterial community structures and soil compositions have significantly changed before and after continuous cropping; however, the effects of continuous cropping on endophytic bacteria of sugar beet were not statistically significant.
\end{abstract}

Conclusion: This study would provide a scientific basis and reference information for in-depth research on correlations between continuous cropping and micro-ecological environment of sugar beet plant.

Keywords: Beta vulgaris, Endophyte, Bacteria, Continuous cropping, Soil, Diversity, Illumina Hiseq 2500

\footnotetext{
* Correspondence: haiyan@ustb.edu.cn; liuyang@ustb.edu.cn;

ly81150@163.com

School of Chemistry and Biological Engineering, University of Science and

Technology Beijing, Beijing 100083, China
}

(c) The Author(s). 2020 Open Access This article is licensed under a Creative Commons Attribution 4.0 International License, which permits use, sharing, adaptation, distribution and reproduction in any medium or format, as long as you give appropriate credit to the original author(s) and the source, provide a link to the Creative Commons licence, and indicate if changes were made. The images or other third party material in this article are included in the article's Creative Commons licence, unless indicated otherwise in a credit line to the material. If material is not included in the article's Creative Commons licence and your intended use is not permitted by statutory regulation or exceeds the permitted use, you will need to obtain permission directly from the copyright holder. To view a copy of this licence, visit http://creativecommons.org/licenses/by/4.0/ 


\section{Introduction}

Sugar beet (Beta vulgaris L.) is a biennial flowering plant originating from Asia and Europe, and it belongs to the Chenopodiaceae family which includes approximately 1400 species and can be divided into 105 genera in the world (Saini and Brar 2018; Abbas et al. 2012; Chhikara et al. 2019). Sugar beet contains a variety of nutrients and active ingredients such as highly active pigments, beet in pigments, ascorbic acid, carotenoids, polyphenols, flavonoids, saponins, and high levels of nitrates (Gamage et al. 2016). These ingredients have antioxidant, anti-inflammatory, anti-cancer, and anti-diabetes functions, and it can help reduce cardiovascular disease and blood pressure and promote wound healing and other ancillary treatments as well as some other health benefits (Sun and Lu 2019). Generally, sugar beet is one of the mostly used raw materials in sugar industry and feed products. High soil fertility and good microecological environment are the basis for obtaining highyield and high-sugar sugar beets (Wang and Yin 2005).

The soil is the substrate for plant growth, providing nutrients to plants and also a habitat for soil microorganisms (Leloup et al. 2018). There are abundant microbial communities in soil, including various pathogens and beneficial bacteria, which promote the stability of soil structure, soil microbial diversity, and ecological balance and are important indicators for maintaining soil productivity (Kirk et al. 2004). These microbial communities can interact with plants, participate in basic nutrient cycling of plants, and play an important role in maintaining plant growth and health (Wang et al. 2017; Schmid et al. 2018; Cao et al. 2018; Liu et al. 2018; Tao et al. 2018; Hussain et al. 2018; Zhao et al. 2018a; Hashami et al. 2019; Das et al. 2019; Tang et al. 2019; Li et al. 2019). Microbes are naturally living in soil and they are important parts of soil ecological environment. They play a vital role in soil formation, fertility changes, and plant growth and are important indicators for measuring soil quality (Brubaker et al. 1992).

As the area of cultivated land continues to shrink, continuous cropping has become a common farming model in agricultural production worldwide. Continuous cropping refers to a system in which certain crops are "replanted" in soils that had previously supported the same or similar plant species (Xiong et al. 2015a). Under continuous cropping conditions, soil enzyme activity is inhibited, microbial dominant communities are alternated; beneficial microbial species and quantity are decreased, harmful pathogenic microorganisms are accumulated and spread, and soil acidification leads to reduced crop yield, poor quality, increased pests and diseases, and decreased soil fertility (Asuming-Brempong et al. 2008). Since the 1980s, scholars from all over the world have done a vast of studies and found out yield reduction of soybeans, cucumbers, cotton, tobacco, wheat, potatoes, sesame, and other crops was due to the continuous cropping obstacles (Hua et al. 2012). These studies have shown that continuous cropping obstacles are not only related to soil physical and chemical properties, but also closely related to soil microbial species and quantities. According to some studies, soil microbial community changes are one of the main causes of continuous cropping obstacles (Hua et al. 2012; Meng et al. 2017).

The rhizosphere is the interface between plant roots and soil, and it is where interactions among a myriad of microorganisms and invertebrates are taken and affect biogeochemical cycling, plant growth, and tolerance to biotic and abiotic stress. The rhizosphere is intriguingly complex and dynamic, and understanding its ecology and evolution is the key to enhancing plant productivity and ecosystem functioning (Philippot et al. 2013). Until now, although there are more and more reports on soil microbes and plants, there are relatively few reports on microbes in sugar beet and its soil (Nielsen and Sorensen 2003; Zachow et al. 2008; Zachow et al. 2014; Kusstatscher et al. 2019).

Plant endophytes are microorganisms that can colonize healthy plant tissues without causing substantial harm to host plants and establish a harmonious symbiotic relationship with plants. They are an important part of the plant micro-ecological system (Liu et al. 2019; Bulgarelli et al. 2013; Philippot et al. 2013). Endophytes would help create a suitable micro-ecological system for their host plants; improve plant physiology, growth, and health by nitrogen-fixing activity; and secrete and induce plant growth regulators, biological control, and other plant growth-promoting components. As a result, they can directly or indirectly affect the agronomic traits and adaptability of their host plants (Kloepper and Beauchamp 1992; van Overbeek and van Elsas 2008; Liu et al. 2012; Liu et al. 2013; Sasaki et al. 2013; Lamit et al. 2014; Liu et al. 2017; Yang et al. 2017a, 2017b; Liu et al. 2019; Zhang et al. 2019).

However, until now, there is relatively few research on the effects of continuous cropping on endophytic diversity and soil microbial community structure of sugar beet plants, from which a series of scientific problems remain to be answered, such as what are the types of endophytic bacteria in sugar beet and its cropping soil under continuous cropping and non-continuous cropping conditions, respectively (Samadi et al. 2008)? What is the relationship between the community structure of endophytes and the indigenous flora in the planted soil under continuous cropping conditions? Is continuous cropping a key factor in the succession of endophytic communities in sugar beet? There are a variety of microbial communities on the surface and inside of plant seeds, present during the growth and development of 
plants, and transmitted from parent to offspring. Therefore, there is a certain relationship between plant microbial communities of different generations (Bergna et al. 2018). In this study, the seeds of sugar beet, continuous and non-continuous cropping sugar beet, and continuous and non-continuous cropping sugar beet soils were used as research materials. High-throughput sequencing (HTS) which is based on Illumina Hiseq 2500 platform was used to reveal the effects of continuous cropping of sugar beet on its endophytic and soil bacterial community structures and diversity. We clarify the bacterial diversity and community structures in each sample, including the seeds of sugar beet, non-continuous cropping sugar beet with its rhizosphere soil and planting soil, and continuous cropping sugar beet with its planting soil, and reveal the relationship and difference of bacterial diversity and community structures between endophytic bacteria in sugar beet tuber and its planting soil. Through a comparative analysis, we are able to reveal the commonalities and differences between the endophytic bacterial community composition of mature beet tuber and the bacteria in soil or seeds under continuous cropping conditions and non-continuous conditions, respectively. This study would provide reference information for further research on the correlation between continuous cropping and plant micro-ecological environment, and also provide a scientific basis for implementing field interventions to improve continuous cropping.

\section{Materials and methods}

\section{Plant and soil sampling}

Sugar beet (Beta vulgaris L.) tuber of non-continuous cropping (sample $\mathrm{Bn}$ ) and its non-continuous cropping soil (sample Sn) and rhizosphere soil (sample Sr), and sugar beet tuber of continuous cropping for 3 years (sample Bc) and its continuous cropping soil (sample Sc) were collected in October 2018 from the sugar beet planting base of Inner Mongolia Liangyi Biotechnology Co., Ltd., in Dalad Banner, Inner Mongolia Autonomous Region ( $40^{\circ} 19^{\prime} 39.62^{\prime \prime} \mathrm{N}, 109^{\circ} 54^{\prime} 55.92^{\prime \prime}$ E, northern China). The seeds of sugar beet (sample S) for planting the above samples in this study were provided by Inner Mongolia Liangyi Biotechnology Co., Ltd. The cultivars of sugar beet seed is H7IM15, and it is widely cultivated in Inner Mongolia Autonomous Region. The soil was classified as desert soil and H7IM15 was planted in new fields and continuously cropped for 1-year fields, respectively. Sugar beet samples were harvested after 7 months of planting. Sugar beet and soil samples were randomly collected, and we took three samples from each plant and three soil samples, then these samples were fully mixed to ensure that our samples were uniform and representative. Sugar beet root was collected from the soil which was $0-40 \mathrm{~cm}$ underground, and the rhizosphere soil sample was collected by shaking. The roots and rhizosphere soil samples were sealed in labeled aseptic plastic bags and placed in an ice chest to transport to the laboratory.

Plant material samples (Bn and $\mathrm{Bc}$ ) and their planting soil samples (Sn and Sc) were used to investigate the effects of continuous cropping on endophytic diversity and soil microbial community structure of sugar beet plants, as well as to reveal the relationship and difference of bacterial diversity and community structures between endophytic bacteria in sugar beet tuber and its planting soil. Seed sample (S) was the common starting sample of sugar beet sample under continuous cropping conditions and non-continuous conditions, which was collected as a plant control sample that was not affected by the environment in this research. Sample Sr (rhizosphere soil sample of sugar beet of non-continuous cropping) was affected by the interactions between plants and soil.

\section{Surface sterilization of plant samples}

Samples S, Bn, and Bc require surface sterilization, while the other three samples do not need to be sterilized. Firstly, the husks of each sugar beet seed sample were removed by a small sheller. Then, the following operations were performed under aseptic conditions in the order as listed here: husked seeds were washed three times with sterile water, $3 \mathrm{~g}$ of seeds was placed in a clean $50-\mathrm{mL}$ sterile tube with $25 \mathrm{~mL}$ phosphate buffer, and the seeds were sonicated twice by an Ultrasonic Processor Scientz-IID sonicator (NingBo Scientz Biotechnology Co., Ltd., China) at low power (237.5 W; $950 \mathrm{~W}$ $\times 25 \%$ ) in an ice bath for 5 min (alternating thirty 2-s bursts and thirty 2-s rests) (Zhang et al. 2019; Liu et al. 2019). To validate the surface was sterilized, sterile tweezers were used to place surface-sterilized seeds into LB medium (LUQIAO), and the seeds were incubated at 30 ${ }^{\circ} \mathrm{C}$ for $72 \mathrm{~h}$. The surface sterilization process of sugar beet tuber was carried out according to Liu et al. (2015). The sugar beet samples were washed with sterile water, immersed in 70\% alcohol for $3 \mathrm{~min}$, washed with fresh sodium hypochlorite solution $\left(2.5 \%\right.$ available $\left.\mathrm{Cl}^{-}\right)$for 5 min, rinsed with $70 \%$ alcohol for $30 \mathrm{~s}$, and finally washed five to seven times with sterile water. Aliquots of the final rinsing water were spread on Luria-Bertani (LB) solid medium plates and cultured for 3 days at $28{ }^{\circ} \mathrm{C}$ for the detection of bacterial colonies. The samples without bacteria on the surface can be used for subsequent analysis.

\section{DNA extraction, amplicon library preparation, and sequencing}

About $5.0 \mathrm{~g}$ of surface-sterilized sugar beet tuber and seed was frozen with liquid nitrogen, and then, the 
samples were quickly grounded into fine powders with a precooled sterile mortar. In this study, $0.5 \mathrm{~g}$ of each soil sample was collected. All the plant and soil samples were extracted using the FastDNA ${ }^{\circ}$ SPIN Kit for Soil (MP Biomedicals, Solon, OH, USA) following the manufacturer's instructions of the Kit. PCR amplification was carried out using primers 338F (5' ${ }^{\prime}$ ACTCCTACGGGAGGCAGCA3'), 806R (5'-GGACTACHVGGGTWTCTAAT-3') designed to amplify the V3-V4 region of the bacterial $16 \mathrm{~S}$ rRNA gene (Klindworth et al. 2013). The PCR uses Phusion (High-Fidelity PCR Master with GC Buffer, NEB). Reaction procedure: initial denaturation at $95{ }^{\circ} \mathrm{C}$ for $5 \mathrm{~min}$, denaturation at $94{ }^{\circ} \mathrm{C}$ for $35 \mathrm{~s}$, annealing at $54{ }^{\circ} \mathrm{C}$ for $35 \mathrm{~s}$, elongation at $72{ }^{\circ} \mathrm{C}$ for $30 \mathrm{~s}$, after 28 circulations, extension at $72{ }^{\circ} \mathrm{C}$ for $8 \mathrm{~min}$. The product was subjected to $1.5 \%$ agarose gel electrophoresis, and the target fragment was observed with blue light. The gel recovery kit (Life Technology, USA) was used for recovery and purification. The recovered and purified product was accurately determined using Qubit 3.0 (Life Technology, USA). Doublestranded DNA concentration was quantified. The number of double-stranded DNA in each sample was set uniformly and mixed into one tube. Amplicon library preparation was conducted according to Liu et al. (2019), and the purified amplicons were pooled in equimolar concentrations. Added library-specific sequencing adapters were added by NEBNext Ultra (NEB\#e7370S/L) assay as followed by the instruction, and dual index sequencing of paired-end 250 bp was run on an Illumina Hiseq2500 instrument (Illumina, San Diego, CA, USA). The sequence data were submitted to NCBI Sequence Read Archive (https://www. ncbi.nlm.nih.gov/sra/), BioProject number was PRJNA530737, and SRA number was SRR8846788SRR8846811.

\section{Quality control of sequencing data}

In total, 1.74 $\mathrm{M}$ raw data was obtained after sequencing and $1.69 \mathrm{M}$ available reads were collected after quality control. After filtering out non-target fragments, a total of about $0.92 \mathrm{M}$ bacterial 16s DNA fragment sequences (ranging from 975 to 100034) were obtained.

\section{Sequence data processing}

Pairs of reads from the raw data were first merged with FLASH version 1.2.7 (Magoč and Salzberg 2011). The forward and reverse reads had the overlapping base length $>10 \mathrm{bp}$ and allow $3 \%$ base mismatch. Sequencing reads were processed with Mothur version 1.31.1. The low-quality sequences (average quality score $<20$ ) and contained ambiguous nucleotides, or did not match the primer (pdiffs $=4$ ) and barcode (bdiffs $=1$ ), were removed (Schloss et al. 2009). Then, the barcode and primer sequences were deleted using Flexbar 3.0 (Roehr et al. 2017). Sequences were taxonomically classified by the Silva database (db128) using RDP algorithm (60\% threshold) (Quast et al. 2013), contaminated sequences (e.g., chloroplast, mitochondria, eukaryota, cyanophyta, cyanobacteria, cercozoa, protista) were removed, and chimera sequences were also removed by applying UCHIME algorithm in Mothur using the "chimera.uchime" command (Edgar et al. 2011). Before dividing OTU, a total of 1,002,433 sequences were removed and these sequences were mainly chloroplasts and mitochondria. Unknown sequences were not present in the original sequence annotation. The remaining high-quality sequences (4313) were grouped into operational taxonomic units (OTUs) at $97 \%$ identity following the studies of Liu et al. (2017). The most abundant sequence in each OTU was identified as the representative sequence, and OTUs of all the samples (Bc, Bn, Sc, Sn, Sr, and S) were assigned with corresponding taxonomies based on the Silva database.

\section{Data statistics}

Diversity index and species richness estimator (alpha-diversity) were calculated using Mothur. Diversity was measured by counting the number of observed OTUs, using the Shannon index and the Simpson index as described by Magurran (O'Keeffe 2004). Species richness for each rDNA gene library was assessed with Chaol indices (Chao 1984). Resampling 2000 sequences per sample with 100 times by "sub.sample" command of Mothur software. The OTU table includes three parallel data of each sample, basing on which the alpha diversity value (including Chao, Shannon, Simpson, and Richness) was calculated and obtained to draw Fig. 1. (Each histogram represents a group; four small maps represent 4 alpha diversity values. The five lines of each column in the figure were from top to bottom: the maximum after quantile statistics, the upper quartile, the median, lower quartile, and minimum, respectively). Beta diversity distance matrix was performed by "vegan" package in R ( $\mathrm{R}$ Core Team 2014). Mantel test analysis, based on Bray-Curtis distance, was used to test relationships between OTU numbers and relative abundances (Anderson and Walsh 2013). Analysis of molecular variance (AMOVA) quantifies the multivariate community-level difference between groups (Meirmans 2006). Venn diagram showed the difference of OTU recovery at species level among the six individual samples. Values in parentheses represented numbers inside each region and indicated the number of unique or shared OTUs (singleton OTUs were removed before the calculation). After removing singleton OTU with a total abundance of OTU, then the Venn diagram was drawn.

\section{Results}

The diversity of bacteria in sugar beet and soil samples

The bacterial communities and diversity in these sugar beet and soil samples showed different OTU richness, 
variable 追 chao $户$ shannon

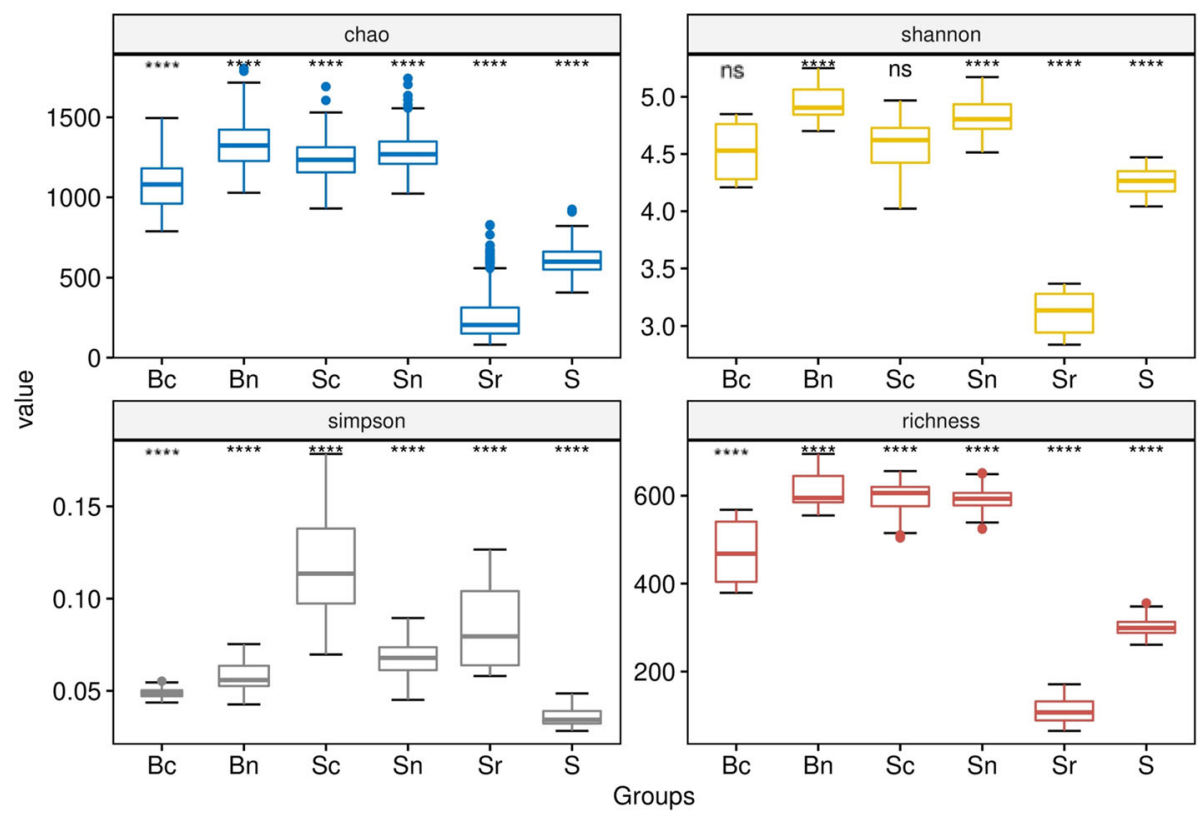

Fig. 1 Alpha diversity boxplot of all sugar beet and soil samples. Bc: sugar beet tuber of continuous cropping; Bn:sugar beet tuber of noncontinuous cropping; Sc: soil of Bc; Sn: soil of Bn; Sr: rhizosphere soil of Bn; S: seeds of sugar beet. Wilcoxon method was used to compare the level of significance and $P$ value of the differences between the samples. Pairwise comparison of each sample and the four asterisks of $P$ value indicate $P<0.0001$, and ns means the difference of Bc vs Sc was not significant

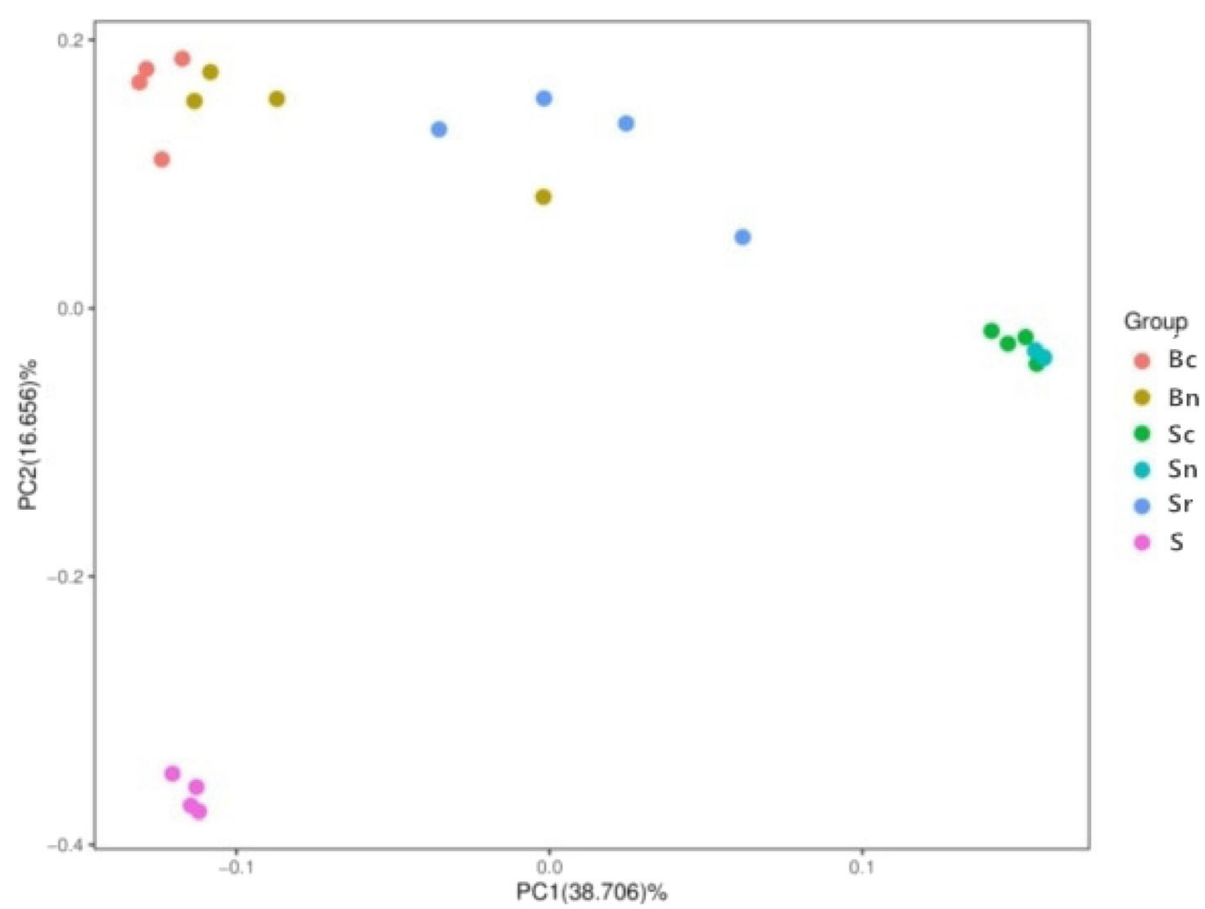

Fig. 2 Beta diversity differences of all sugar beet and soil samples. Bc: sugar beet tuber of continuous cropping; Bn:sugar beet tuber of noncontinuous cropping; Sc: soil of Bc; Sn: soil of Bn; Sr: rhizosphere soil of Bn; S: seeds of sugar beet 
and they were cleaned and classified into 4313 OTUs at $97 \%$ sequence similarity level. In order to accurately calculate the alpha diversity value, "sub.sample" command of Mothur software was used to draw the OTU table and 2715 OTUs were left after singleton removal. Based on the statistical results of bacterial alpha diversity in each sample, the Chao1, Richness, Simpson and Shannon values, and boxplot were shown in Fig. 1 . In the randomly selected six samples, the Wilcoxon method was used to compare the level of significance and $P$ value of the differences between the samples. The $P$ values were summarized in Additional file 1: Table S1 and added to Fig. 1. The alpha diversity indexes showed only $\mathrm{Bc}$ and Sc were not significantly different, and the other comparisons all showed significant differences. The Chao1 and Shannon values of samples Bn and Sn were higher than those of $\mathrm{Bc}$ and Sc, respectively, and the difference was significant. (Bn vs Bc, $P=3.90 \mathrm{E}-104$, 7.95E-144; Sn vs Sc, $P=6.64 \mathrm{E}-14$; 3.10E-120; Bn vs Sc, $P=1.38 \mathrm{E}-36,4.72 \mathrm{E}-190 ; \mathrm{Sn}$ vs Bc, $P=2.53 \mathrm{E}-99,9.22 \mathrm{E}$ -70 , respectively). The bacterial richness of samples $\mathrm{Sr}$ and $\mathrm{S}$ were much lower than samples $\mathrm{Bc}, \mathrm{Bn}, \mathrm{Sc}$, and Sn, and similar results were obtained from Chaol and
Shannon indexes. (Sr vs Sc, $P=8.89 \mathrm{E}-263,8.89 \mathrm{E}-263$; Sr vs $\mathrm{Sn}, P=8.89 \mathrm{E}-263$, 8.89E-263; Sr vs Bc, $P=7.70 \mathrm{E}$ -176, 7.55E-176; Sr vs Bn, $P=1.60 \mathrm{E}-225,1.60 \mathrm{E}-225$; $\mathrm{S}$ vs $\mathrm{Bc}, P=3.90 \mathrm{E}-104,1.10 \mathrm{E}-51$; $\mathrm{S}$ vs $\mathrm{Bn}, P=1.60 \mathrm{E}-225$, $1.60 \mathrm{E}-225 ; \mathrm{S}$ vs Sc, $P=8.89 \mathrm{E}-263,7.48 \mathrm{E}-97$; $\mathrm{S}$ vs $\mathrm{Sn}, P$ $=8.89 \mathrm{E}-263,8.89 \mathrm{E}-263$, respectively). The richness of endophytic bacteria in sample $S$ was $299.99 \pm 16.66$, it was the lowest value compared to samples Bc (609.05 \pm 34.14) and $\mathrm{Bn}(472.67 \pm 68.96)$ (Fig. 1). The results showed that after continuous cropping, the diversity of bacteria in sugar beet and soil samples were changed, and the bacterial richness in sugar beet and its planting soil was much higher than in seeds and rhizosphere soil. It indicated that continuous cropping and different kinds of samples would affect the richness and diversity of bacteria in plants and soil.

\section{Bacterial community structures and compositions in sugar beet and soil samples}

The mantel test calculation results showed that there was a strong correlation $(r=0.9967, P=0.001)$ between Bray-Curtis dissimilarity metrics based on bacterial genera level classification and OTU table. ANOSIM analysis
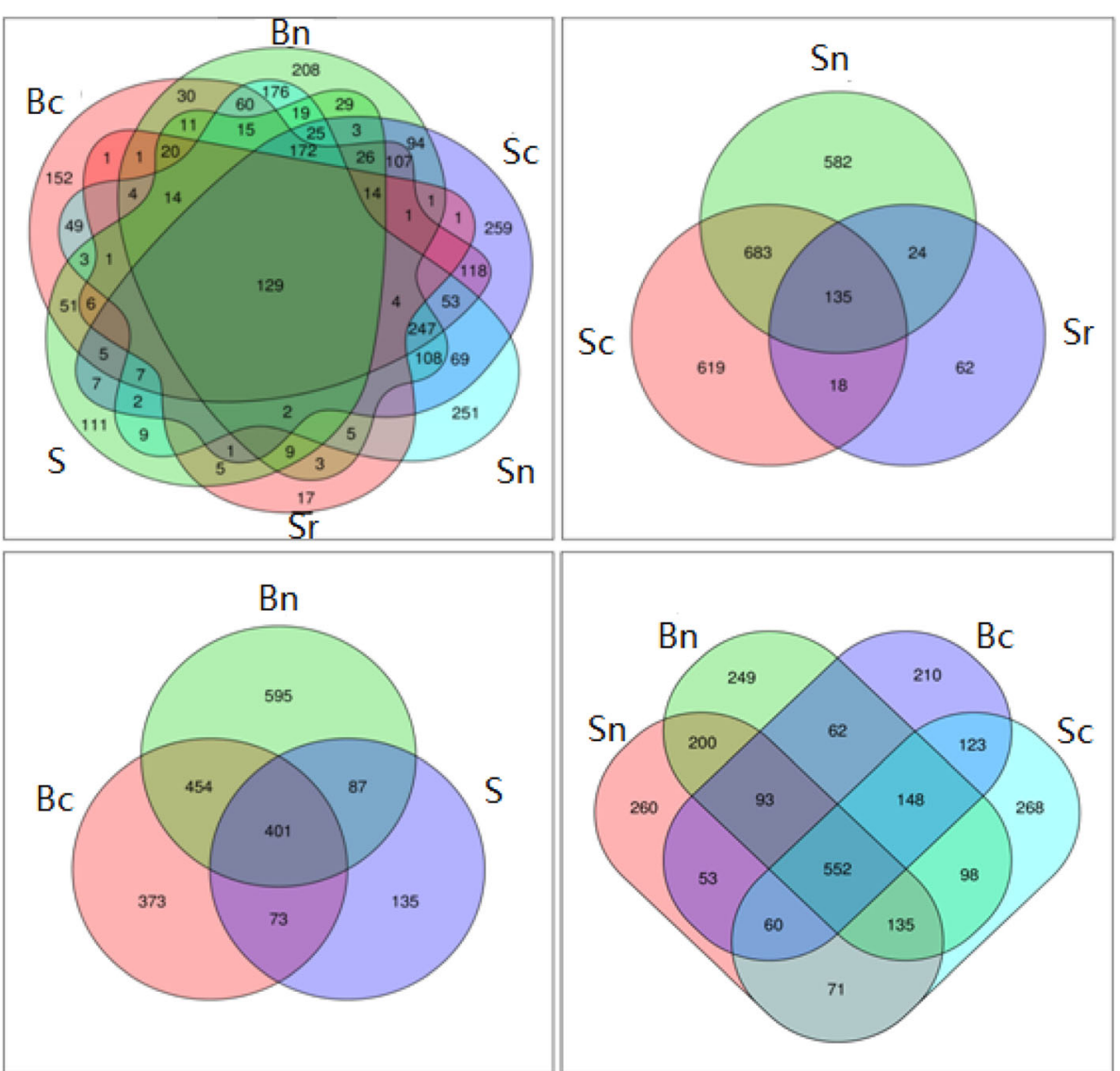

Fig. 3 Venn diagram of OTUs in all sugar beet and soil samples. Bc: sugar beet tuber of continuous cropping; Bn:sugar beet tuber of noncontinuous cropping; Sc: soil of Bc; Sn: soil of Bn; Sr: rhizosphere soil of Bn; S: seeds of sugar beet 
was performed to analyze the beta diversity difference between samples, and the results confirmed that there existed significant differences in all pairwise comparisons, except "Bc versus Bn" which was shown in Fig. 2.

All six samples were used to plot the Venn diagram (Fig. 3) which was used to investigate whether shared endophytic OTUs were existed or not. At $97 \%$ similarity level, the numbers of OTUs for samples Bc, Bn, Sc, Sn, Sr, and S were 1301, 1537, 1455, 1424, 239, and 696, respectively. It was clear that the endophytic bacterial of sample $\mathrm{S}$ was less than other sugar beet samples. Among samples Sn, Sc, and Sr, 135 bacterial OTUs coexisted in all three soil samples while each sample contained its unique OTUs. There were 129 shared OTUs coexisted in all six samples, and the relative abundances of different phyla and genera in all samples were shown in Figs. 4 and 5. The results showed that the phyla of Actinobacteria, Proteobacteria, Firmicutes, Acidobacteria, Bacteroidetes, Chlorofiexi, and Gemmatimonadetes existed in all soil and plant samples. Nitrospirae, Saccharibacteria, and Verrucomicrobia were not present in both samples $\mathrm{Sr}$ and $\mathrm{S}$, while these appeared in samples $\mathrm{Bn}, \mathrm{Bn}, \mathrm{Sn}$, and Sc. According to Fig. 5, the proportions of unique OTUs were $42.5 \%, 40.9 \%$, and $25.9 \%$ in samples Sc, Sn, and Sr, respectively. The bacterial groups shared in these three soil samples included Pseudarthrobacter, Bacillus, Planococcus, Paracoccus, Nocardioides, and Nesterenkonia were present. The composition of the bacterial community was different in plant samples and soil samples. The bacteria genus of Aerococcus, Aeromicrobium, and Galella existed in soil samples, which are not found in plant samples. In addition, top 5\% taxa classification from phylum to genera level in each sample was plotted to reveal the differences of bacteria compositions in all six samples (Fig. 6).

In this study, the bacterial community structures and compositions in the soil had undergone some changes before and after continuous cropping, while the effects of continuous cropping on endophytic bacteria of sugar beet were not statistically significant. There were Sphingomonas, Pseudarthrobacter, Paracoccus, Planococcus, Novosphingobium, Nesterenkonia, Nocardioides, Acinetobacter, Bacillus, and Halomonas in non-continuous soil sample Sn. Under continuous cropping conditions, the genera of bacteria in sample Sc included Acinetobacter, Bacillus, Halomonas, Nesterenkonia, Nocardioides, Paracoccus, Planococcus, Pseudarthrobacter, Sphingomonas, and Terribacillus. The bacteria genus of Novosphingobium was present in the sample Sn, while we did not find this bacterium in the sample Sc. In addition, we found that Terribacillus was not appeared in sample Sn, while this bacterium was included in the sample Sc and it was also included in samples Sr and Bc. Under continuous cropping condition, the genera of endophytic bacteria in soil were different from non-continuous cropping. There are some differences in the diversity and compositions of the microbial communities in the samples Sn and Sc. From the results mentioned above, it

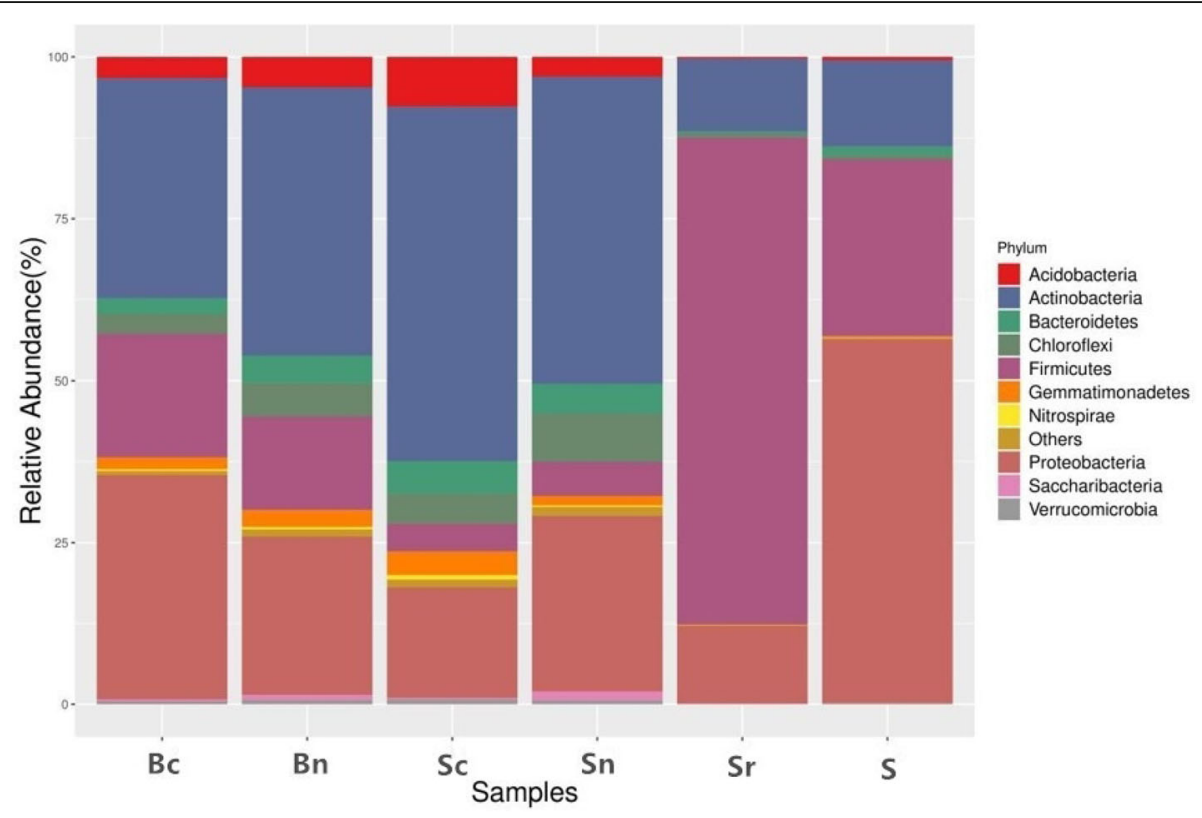

Fig. 4 Relative abundance at phylum level in each sample. Three internal averages of each group were taken to get six columns of OTU tables. Combine the phylum-genera annotations in which each OTU represented the sequence, and the above table. The absolute value of each species at the phylum-genera level was obtained, converted to a percentage, and then plotted. The figure showed the top 10 phyla with the highest total content, while the rest were merged into others 

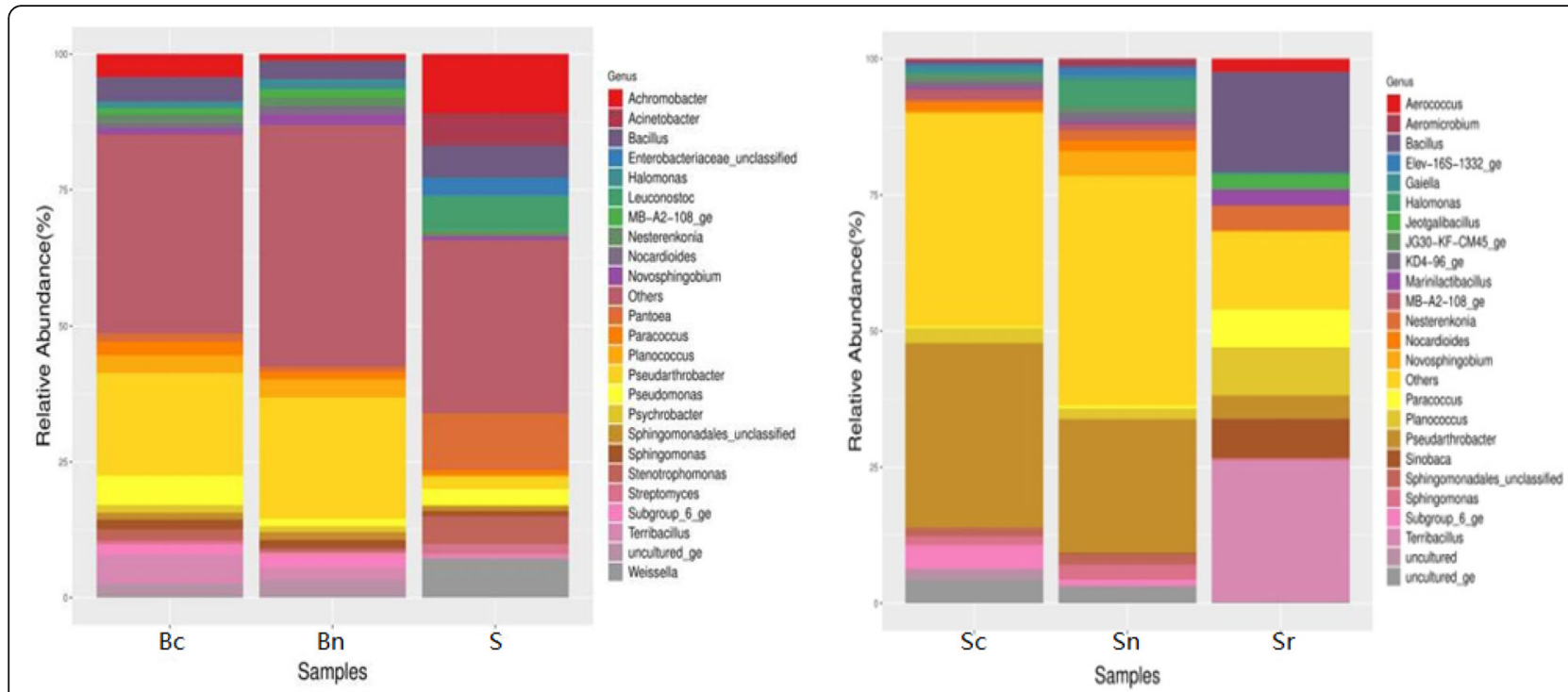

Fig. 5 Relative abundance of shared/unshared genera in each sample. The top 24 genera of each sample were selected, and the less abundant taxa were grouped in "others"

indicated that the bacterial community compositions in soil have changed before and after continuous cropping. Among these three plant samples, the endophytic bacterial groups included Pseudarthrobacter, Bacillus, Achromobacter, Pantoea, Pseudomonas, Sphingomonas, Novosphingobium, Stenotrophomonas, Terribacillus, Paracoccus, Nesterenkonia, Weissella, Leuconostoc, and Nocardioides. The endophytic bacterial genus Acinetobacter was present in the samples S, but not in the samples Bn and Bc. The
Novosphingobium was not included in the sample S, while we found it in the samples Bn and Bc.

\section{Discussion}

Sugar beet is not only the world's main sugar crop but also one of China's main sugar crops, and its production plays an important role in the national economy, especially in sugar industry (Sun and Lu 2019). Related research on endophytic and soil microorganisms of sugar

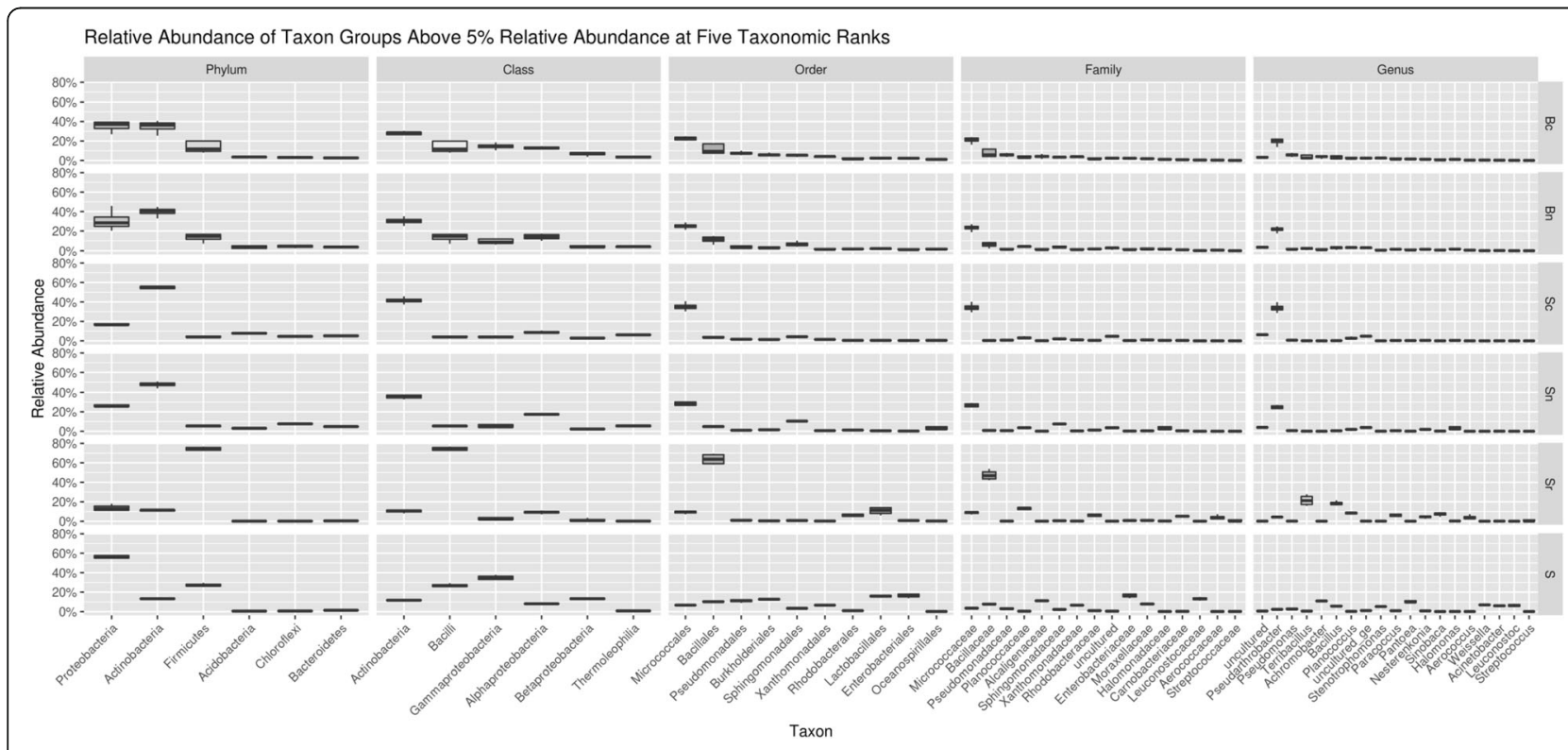

Fig. 6 Relative abundance of taxon groups above $5 \%$ at five taxonomic ranks. Each boxplot in the figures indicated the range of bacteria genera observations in each sample, with the box denoting the interquartile range (IQR) between the first and third quartiles (i.e., 25th and 75th percentiles, respectively) and the vertical line inside the box defined the median. In order to better show the difference in bacterial species between the groups, more than 5\% of all samples (six groups), in any one group, were counted (from phylum to genera) and plotted 
beet is important in improving the cultivation level and development of beet sugar industry. In this study, the effects of continuous cropping of sugar beet on its endophytic and soil bacterial community structure and diversity were investigated by high-throughput sequencing (HTS) based on Illumina Hiseq 2500 platform.

Plant continuous cropping has significant impacts on the physical and chemical properties of soil, and the community structures of soil microbes. In order to investigate the effects of continuous cropping of many crops on its soil microbes, as well as the yield and quality of plants (Asuming-Brempong et al. 2008), recent studies included sweet potato ( $\mathrm{Li}$ et al. 2019), Vanilla (Xiong et al. 2015b), rice (Kumar et al. 2017), maize (Wang et al. 2018), coffee (Zhao et al. 2018b), peanut (Xie et al. 2019), Pinellia ternate (He et al. 2019), cotton (Luan et al. 2015), cucumber, watermelon (Shen et al. 2017), Panax notoginseng (Dong et al. 2016), and ramie (Zhu et al. 2018). These findings provided an overview of soil weakness and indicated that the increased disease in plants after long-term continuous cropping can be caused by changes in soil microbes, which means there was a reduction in beneficial microbes and an accumulation of harmful microbes. Rhizobacteria and endophytic bacteria can protect host plants from phytopathogens' infection, which may lead to soil-borne diseases and severely impair plant health (Tan et al. 2017a, 2017b). Recent studies confirmed that plant continuous cropping was one of the factors which caused changes in plant rhizospheric and endophytic communities (Peng et al. 2014; Tan et al. 2017a; Tan et al. 2017b; Cui et al. 2018; Xie et al. 2019).

The results showed that the diversity values of sample $\mathrm{Sr}$ was lower than samples $\mathrm{Sn}$ and Sc, which might be due to the $\mathrm{pH}$ inside plant roots did not permit growth of rhizosphere bacteria, or perhaps a combination of these effects and other edaphic and environmental factors. Based on Yang's research (2017), this result might be that the selection of rhizosphere microorganisms by the roots leads to the differences in bacterial diversity in the rhizosphere and soil. We also found bacterial richness of samples $\mathrm{Sr}$ and $\mathrm{S}$ was the lowest in soil and plant samples, respectively. This might be due to the relatively limited space and capacity in the rhizosphere and seeds compared to sugar beet tuber and its environmental soil. The comparison of sample $\mathrm{Sr}$ with samples $\mathrm{Bn}$ and $\mathrm{BC}$ showed that the diversity value of $\mathrm{Sr}$ was lower than that of samples $\mathrm{Bn}$ and $\mathrm{Bc}$, which might be due to the common influence of seeds and soil, and its endophytic bacteria were constantly changing as the plant grows. According to our results, the diversity values of samples $\mathrm{Bn}$ and $\mathrm{Sn}$ were higher than samples $\mathrm{Bc}$ and Sc under continuous cropping conditions, respectively (Fig. 3). Based on Li's research (2019), this result might be related to a significant decline in soil organic carbon and soil bacterial abundance due to continuous cropping. Our study showed that microbial diversity and communities in soil and host plant seeds had an impact on the endophytic composition and community structures under continuous cropping. The result was consistent with many previous research reports which were about two main sources of endophytic bacteria in plants: one was the external environment of the plant surface and the other was the plant seed (Sessitsch et al. 2002; Ferreira et al. 2008; Hardoim et al. 2008; Mano and Morisaki 2008; Liu et al. 2019).

The above results showed that sugar beet plant samples $\mathrm{Bn}$ and $\mathrm{Bc}$ and their soil samples $\mathrm{Sn}$ and Sc have the same group, Pseudarthrobacter (Fig. 5). It was reported that Pseudarthrobacter can be isolated from soil, desert, and mine (Ben Fekih et al. 2018; Finger et al. 2019; Chai et al. 2019), and at low temperature, Pseudarthrobacter sulfonivorans strain Ar51 can efficiently degrade crude oil and multi benzene compounds (Zhang et al. 2016). Differences in bacterial community structures and group abundance between the treatments of continuous cropping and non-continuous cropping were shown based on results in this research. The genus of Pantoea was found in plant seeds (Mano et al. 2006; Jiang et al. 2013; Zhang et al. 2019), and several species of Pantoea were often reported as common plant growth-promoting bacteria (PGPB) (Liu et al. 2019). Pantoea, Pseudomonas, Stenotrophomonas, Weissella, Leuconostoc, and Acinetobacter were common endophytes often found in several plants by our research group (Liu et al. 2012; Liu et al. 2013; Liu et al. 2015; Liu et al. 2017; Liu et al. 2019), and they may come from the environment (such as air and rain) or the seed but not from the soil during the growth of the plant.

It is worth mentioning that the bacterial community structures and compositions in the soil of continuous cropping had undergone some changes compared to non-continuous cropping in this study. Soil bacterial groups, including Bacillus, Paracoccus, Sphingomonas, Novosphingobium, and Halomonas, were reduced under continuous cropping of sugar beet plant, and some species of these groups have been previously identified as common PGPB, which may directly or indirectly influence the growth and development of host plants (Liu et al. 2012; Xu et al. 2014; Desale et al. 2014; Yadav et al. 2015; Banik et al. 2016; Lafi et al. 2016; RodriguezConde et al. 2016; Rangjaroen et al. 2017; Vives-Peris et al. 2018; Liu et al. 2019; Sahoo et al. 2019). This result directly reflected that continuous cropping of sugar beet played an important role in bacterial community compositions and diversity in the soil environment, and this was consistent with previous research reports on other crops (Asuming-Brempong et al. 2008; Kumar et al. 
2017; Wang et al. 2018; Zhu et al. 2018; Li et al. 2019). However, the main endophytic bacterial groups and community structure in this study were similar among sugar beet tuber samples of non-continuous cropping and continuous cropping. Tan et al. (2017a) found that during continuous cropping practices, the effects of $P$. notoginseng on endophytic bacteria were not statistically significant. Plant continuous cropping directly affected the microbial community structure and physicochemical properties of soil, but the effects of continuous cropping on plant endophytes were indirect. At the same time, the direct influence of host plants on their endophytes was also a significant factor that could not be ignored. Many studies have confirmed that plant varieties, genotypes, growth period, and so on played an important role in related endophytic microbial diversity and community structures; besides, the endophytes would establish a suitable micro-ecological system for their host plants (van Overbeek and van Elsas 2008; Liu et al. 2012; Liu et al. 2013; Lamit et al. 2014; Liu et al. 2019).

The bacterial communities and diversity in each sample exhibited different OTU richness, $67.9 \%$ and $63.8 \%$ of total OTUs from samples Bc and Bn were shared with $\mathrm{Sc}$ and Sn, respectively, and shared $36.4 \%$ and $31.8 \%$ of total OTUs with their seed sample $\mathrm{S}$. The main shared bacterial groups among all samples were Pseudarthrobacter and Bacillus. Endophytic bacterial groups shared in three plant samples included Pseudarthrobacter, Bacillus, Achromobacter, Pantoea, Pseudomonas, Sphingomonas, Novosphingobium, Stenotrophomonas, Terribacillus, Paracoccus, Nesterenkonia, Weissella, Leuconostoc, and Nocardioides. Among the three soil samples, Pseudarthrobacter, Bacillus, Planococcus, Paracoccus, Nesterenkonia, and Nocardioides were shared. The bacterial community structures and compositions in the soil had undergone some changes before and after continuous cropping, while the effects of continuous cropping on endophytic bacteria of sugar beet were not statistically significant. This is the first study on bacterial community structure and diversity of sugar beet endophytic and soil under continuous cropping. It provides scientific clues for future research on continuous cropping and micro-ecological environment of sugar beet, as well as the implementation of field interventions for continuous cropping soil.

\section{Supplementary information}

Supplementary information accompanies this paper athttps://doi.org/10. 1186/s13213-020-01583-8.

Additional file 1: Table S1. The level of significance and $P$ value for differences in diversity index.

\section{Acknowledgements}

We sincerely thank Dr. Yi Xiao at Johns Hopkins University (USA) and Dr. Shahbaz Ahmad at the University of Science and Technology Beijing for assistance with the English language and grammatical editing of the manuscript.

Ethics approval and consent to participate

This article does not contain any studies with human participants or animals performed by any of the authors.

\section{Authors' contributions}

Miao Li carried out the bacterial community studies, participated in the sequence alignment and drafted the manuscript. Fuzhen Yang carried out the sample collection. Xianyu Wu participated in the sequence alignment and performed the statistical analysis. Hai Yan and Yang Liu conceived of the study and participated in its design and coordination. All authors read and approved the final manuscript.

\section{Funding}

This work was supported by the Fundamental Research Funds for the Central Universities (No. FRF-TP-18-012A1, FRF-BR-18-009B) and the University-Enterprise Cooperation Project "Application Research of Microorganisms in Agriculture and Environmental Protection" (No. 2018-854).

Ethics approval and consent to participate

Not applicable.

\section{Competing interests}

The authors declare that they have no competing interests.

Received: 15 October 2019 Accepted: 13 May 2020

Published online: 22 June 2020

References

Abbas F, Mohanna A, Al-Lahham G, AL-Jbawi E (2012) Osmotic adjustment in sugar beet plant under salinity stress. J Sugar Beet 28(1):37-43

Anderson MJ, Walsh DCI (2013) PERMANOVA, ANOSIM, and the Mantel test in the face of heterogeneous dispersions: what null hypothesis are you testing? Ecol Monogr 83(4):557-574

Asuming-Brempong S, Gantner S, Adiku SGK, Archer G, Edusei V, Tiedje JM (2008) Changes in the biodiversity of microbial populations in tropical soils under different fallow treatments. Soil Biol Biochem 40(11):2811-2818

Banik A, Mukhopadhaya SK, Dangar TK (2016) Characterization of N2-fixing plant growth promoting endophytic and epiphytic bacterial community of Indian cultivated and wild rice (Oryza spp.) genotypes. Planta 243(3):799-812

Ben Fekih I, Ma Y, Herzberg M, Zhang C, Li YP, Mazhar SH, Bello SK, Yang N, Su J, Xu J, Zhang R, Feng R, Chen Z, Rensing C (2018) Draft genome sequence of Pseudarthrobacter sp. strain AG30, isolated from a gold and copper mine in China. Microbiol Resour Announc 7(17):e01329-e01318

Bergna A, Cernava T, Rändler M, Grosch R, Zachow C, Berg G (2018) Tomato seeds preferably transmit plant beneficial endophytes. Phytobiomes J 2(4): 183-193

Brubaker HW, Dumas AR, Meaney JJ, O'Neil JAS, Onsi DE, Corzilius DB (1992) Conserving biological diversity in agricultural/forest systems. Bioscience 42 : 354-362

Bulgarelli D, Schlaeppi K, Spaepen S et al (2013) Structure and functions of the bacterial microbiota of plants. Annu Rev Plant Biol 64:807-838

Cao B, Zhang Y, Wang Z, Li M, Yang F, Jiang D, Jiang Z (2018) Insight into the variation of bacterial structure in atrazine-contaminated soil regulating by potential phytoremediator: Pennisetum americanum (L.) K. Schum. Front Microbiol 9:864

Chai X, Wang L, Yang Y, Xie L, Zhang J, Wu T, Zhang X, Xu X, Wang Y, Han Z (2019) Apple rootstocks of different nitrogen tolerance affect the rhizosphere bacterial community composition. J Appl Microbiol 126(2):595-607

Chao A (1984) Nonparametric estimation of the number of classes in a population. Scand J Stat 11(4):265-270

Chhikara N, Kushwaha K, Sharma P, Gat Y, Panghal A (2019) Bioactive compounds of beetroot and utilization in food processing industry: a critical review. Food Chem 272:192-200

Cui J, Bai L, Liu X, Jie W, Cai B (2018) Arbuscular mycorrhizal fungal communities in the rhizosphere of a continuous cropping soybean system at the seedling stage. Braz J Microbiol 49(2):240-247 
Das S, Gwon HS, Khan MI, Van Nostrand JD, Alam MA, Kim PJ (2019) Taxonomic and functional responses of soil microbial communities to slag-based fertilizer amendment in rice cropping systems. Environ Int 127:531-539

Desale P, Patel B, Singh S, Malhotra A, Nawani N (2014) Plant growth promoting properties of Halobacillus sp. and Halomonas sp. in presence of salinity and heavy metals. J Basic Microbiol 54(8):781-791

Dong L, Xu J, Feng G, Li X, Chen S (2016) Soil bacterial and fungal community dynamics in relation to Panax notoginseng death rate in a continuous cropping system. Sci Rep 6:31802

Edgar RC, Haas BJ, Clemente JC, Quince C, Knight R (2011) UCHIME improves sensitivity and speed of chimera detection. Bioinformatics 27(16):2194-2200

Ferreira A, Quecine MC, Lacava PT, Oda S, Azevedo JL, Araújo WL (2008) Diversity of endophytic bacteria from Eucalyptus species seeds and colonization of seedlings by Pantoea agglomerans. FEMS Microbiol Lett 287(1):8-14

Finger S, Godoy FA, Wittwer G, Aranda CP, Calderón R, Miranda CD (2019) Purification and characterization of indochrome type blue pigment produced by Pseudarthrobacter sp. 34LCH1 isolated from Atacama desert. J Ind Microbiol Biotechnol 46(1):101-111

Gamage SM, Mihirani MKS, Perera ODAN, Weerahewa HLD (2016) Development of synbiotic beverage from beetroot juice using beneficial probiotic Lactobacillus Casei 431. Ruhuna J Sci 7:64-69

Hardoim PR, van Overbeek LS, van Elsas JD (2008) Properties of bacterial endophytes and their proposed role in plant growth. Trends Microbiol 16(10):463-471

Hashami SZ, Nakamura H, Ohkama-Ohtsu N, Kojima K, Djedidi S, Fukuhara I, Haidari MD, Sekimoto H, Yokoyama T (2019) Evaluation of immune responses induced by simultaneous inoculations of soybean (Glycine max [L.] Merr.) with soil bacteria and rhizobia. Microbes Environ 34(1):64-75

He Z, Chen H, Liang L, Dong J, Liang Z, Zhao L (2019) Alteration of crop rotation in continuous Pinellia ternate cropping soils profiled via fungal ITS amplicon sequencing. Lett Appl Microbiol. https://doi.org/10.1111/lam.13135

Hua JL, Liu GR, Huang JS (2012) Effect of continuous cropping of sesame on rhizospheric microbial communities. Acta Ecol Sin 32(9):2936-2942

Hussain M, Hamid MI, Tian J, Hu J, Zhang X, Chen J, Xiang M, Liu X (2018) Bacterial community assemblages in the rhizosphere soil, root endosphere and cyst of soybean cyst nematode-suppressive soil challenged with nematodes. FEMS Microbiol Ecol 94(10). https://doi.org/10.1093/femsec/fiy142

Jiang XY, Gao JS, Xu FH, Cao YH, Tang X, Zhang XX (2013) Diversity of endophytic bacteria in rice seeds and their secretion of indole acetic acid (in (Chinese). Acta Microbiol Sin 53:269-275

Kirk JL, Beaudette LA, Hart M, Moutoglis P, Klironomos JN, Lee H, Trevors JT (2004) Methods of studying soil microbial diversity. J Microbiol Methods 58(2):169-188

Klindworth A, Pruesse E, Schweer T, Peplies J, Quast C, Horn M, Glöckner FO (2013) Evaluation of general 165 ribosomal RNA gene PCR primers for classical and next-generation sequencing-based diversity studies. Nucleic Acids Res 41(1):e1

Kloepper JW, Beauchamp CJ (1992) A review of issues related to measuring colonization of plant roots by bacteria. Can J Microbiol 38:1219-1232

Kumar U, Berliner J, Adak T, Rath PC, Dey A, Pokhare SS, Jambhulkar NN, Panneerselvam P, Kumar A, Mohapatra SD (2017) Non-target effect of continuous application of chlorpyrifos on soil microbes, nematodes and its persistence under sub-humid tropical rice-rice cropping system. Ecotoxicol Environ Saf 135:225-235

Kusstatscher P, Zachow C, Harms K, Maier J, Eigner H, Berg G, Cernava T (2019) Microbiome-driven identification of microbial indicators for postharvest diseases of sugar beets. Microbiome 7(1):112

Lafi FF, Ramirez-Prado JS, Alam I, Bajic VB, Hirt H, Saad MM (2016) Draft genome sequence of Halomonas elongata strain K4, an endophytic growthpromoting bacterium enhancing salinity tolerance in planta. Genome Announc 4(6):e01214-e01216

Lamit L, Lau MK, Sthultz CM, Wooley SC, Whitham TG, Gehring CA (2014) Tree genotype and genetically based growth traits structure twig endophyte communities. Am J Bot 101:467-478

Leloup J, Baude M, Nunan N, Meriguetc J, Dajoza I, Rouxd XL, Xavier Raynauda X (2018) Unravelling the effects of plant species diversity and aboveground litter input on soil bacterial communities. Geoderma 317:1-7

Li H, Wang J, Liu Q, Zhou Z, Chen F, Xiang D (2019) Effects of consecutive monoculture of sweet potato on soil bacterial community as determined by pyrosequencing. J Basic Microbiol 59(2):181-191
Liu Y, Li YH, Yao S, Wang H, Cao YH, Li J, Bai FR, Qiu CZ, Feng X, Dai WK, Cheng C (2015) Diversity and distribution of endophytic bacterial community in the Noni (Morinda citrifolia L.) plant. Afr J Microbiol Res 9(25):1649-1657

Liu Y, Wang RH, Li YH, Cao YH, Chen CY, Qiu CZ, Bai FR, Xu TJ, Zhang X, Dai WK, Zhao JR, Cheng C (2017) High-throughput sequencing-based analysis of the composition and diversity of endophytic bacterial community in seeds of hybrid maize planted in China. Plant Growth Regul 81:317-324

Liu Y, Xu PP, Yang FZ, Li M, Yan H, Li N, Zhang XX, Wang WP (2019) Composition and diversity of endophytic bacterial community in seeds of super hybrid rice 'Shenliangyou 5814' (Oryza sativa L.) and its parental lines. Plant Growth Regul 87:257-266

Liu Y, Zuo S, Xu LW, Zou YY, Song W (2012) Study on diversity of endophytic bacterial communities in seeds of hybrid maize and their parental lines. Arch Microbiol 194:1001-1012

Liu Y, Zuo S, Zou YY, Wang JH, Song W (2013) Investigation on diversity and population succession dynamics of endophytic bacteria from seeds of maize (Zea mays L., Nongda108) at different growth stages. Ann Microbiol 63:71-79

Liu Z, Wang LA, Ding S, Xiao H (2018) Enhancer assisted-phytoremediation of mercury-contaminated soils by Oxalis corniculata L., and rhizosphere microorganism distribution of Oxalis corniculata L. Ecotoxicol Environ Saf 160: $171-177$

Luan FG, Zhang LL, Lou YY, Wang L, Liu YN, Zhang HY (2015) Analysis of microbial diversity and niche in rhizosphere soil of healthy and diseased cotton at the flowering stage in southern Xinjiang. Genet Mol Res 14(1): 1602-1611

Magoč T, Salzberg SL (2011) FLASH: fast length adjustment of short reads to improve genome assemblies. Bioinformatics 27(21):2957-2963

Mano H, Morisaki H (2008) Endophytic bacteria in the rice plant. Microbes Environ 23(2):109-117

Mano H, Tanaka F, Watanabe A, Kaga H, Okunishi S, Morisaki H (2006) Culturable surface and endophytic bacterial flora of the maturing seeds of rice plants (Oryza sativa) cultivated in a paddy field. Microbes Environ 21:86-100

Meirmans PG (2006) Using the AMOVA framework to estimate a standardized genetic differentiation measure. Evolution 60(11):2399-2402

Meng FG, Zhang MH, Rao DM, Zhang W, Qiu Q, Zhao J, Yan XY, Yao LY (2017) Effects of continuous soybean and crop rotation on soil microbial diversity. Soybean Sci Technol 6:10-15

Nielsen TH, Sorensen J (2003) Production of cyclic lipopeptides by Pseudomonas fluorescens strains in bulk soil and in the sugar beet rhizosphere. Appl Environ Microbiol 69(2):861-868

O'Keeffe J (2004) Measuring biological diversity. Afr J Aquat Sci 29(2):285-286

Peng SM, Wang BL, Xu JZ, Ding ZS, Yuan XF (2014) Effect of different treatment on endophytic bacterial communities in continuous cropping of Chrysanthemum morifoliu. Chin J Chin Materia Medica 9(24):4763-4768 (in Chinese)

Philippot L, Raaijmakers JM, Lemanceau P (2013) Going back to the roots: the microbial ecology of the rhizosphere. Nat Rev Microbiol 11(11):789-799

Quast C, Pruesse E, Yilmaz P, Gerken J, Schweer T, Yarza P, Glöckner FO (2013) The SILVA ribosomal RNA gene database project: improved data processing and web-based tools. Nucleic Acids Res 41(D1):D590-D596

R Core Team (2014) R: a language and environment for statistical computing. $R$ Foundation for Statistical Computing, Vienna

Rangjaroen C, Sungthong R, Rerkasem B, Teaumroong N, Noisangiam R, Lumyong S (2017) Untapped endophytic colonization and plant growthpromoting potential of the genera Novosphingobium to optimize rice cultivation. Microbes Environ 32(1):84-87

Rodriguez-Conde S, Molina L, González P, García-Puente A, Segura A (2016) Degradation of phenanthrene by Novosphingobium sp. HS2a improved plant growth in PAHs-contaminated environments. Appl Microbiol Biotechnol 100(24):10627-10636

Roehr JT, Dieterich C, Reinert K (2017) Flexbar 3.0-SIMD and multicore parallelization. Bioinformatics 33(18):2941-2942

Sahoo B, Ningthoujam R, Chaudhuri S (2019) Isolation and characterization of a lindane degrading bacteria Paracoccus sp. NITDBR1 and evaluation of its plant growth promoting traits. Int Microbiol 22(1):155-167

Saini KS, Brar NS (2018) Crop and water productivity of sugarbeet (Beta vulgaris) under different planting methods and irrigation schedules. Agric Res 7(1):93-97

Samadi A, Dovlati B, Barin M (2008) Effect of continuous cropping on potassium forms and potassium adsorption characteristics in calcareous soils of Iran. Aust J Soil Res 46(3):265-272 
Sasaki K, Ikeda S, Ohkubo T, Kisara C, Sato T, Minamisawa K (2013) Effects of plant genotype and nitrogen level on bacterial communities in rice shoots and roots. Microbes Environ 28:391-395

Schloss PD, Westcott SL, Ryabin T, Hall JR, Hartmann M, Hartmann M, Hollister EB, Lesniewski RA, Oakley BB, Parks DH, Robinson CJ, Sahl JW, Stres B, Thallinger GG, Van Horn DJ, Weber CF (2009) Introducing Mothur: open-source, platform-independent, community-supported software for describing and comparing microbial communities. Appl Environ Microbiol 75:7537-7541

Schmid MW, Hahl T, van Moorsel SJ, De Deyn GB, Bernhard Schmid B (2018) Rhizosphere bacterial community composition depends on plant diversity legacy in soil and plant species identity. BioRxiv 287235

Sessitsch A, Reiter B, Pfeifer U, Wilhelm E (2002) Cultivation-independent population analysis of bacterial endophytes in three potato varieties based on eubacterial and Actinomycetes-specific PCR of $16 \mathrm{~S}$ rRNA genes. FEMS Microbiol Ecol 39(1):23-32

Shen ZZ, Sun L, Wang DS, Lyu NN, Xue C, Li R, Shen QR (2017) Effects of limeammonium bicarbonate fumigation and biofertilizer application on Fusarium wilt and biomass of continuous cropping cucumber and watermelon. Chin J Appl Ecol 28(10):3351-3359 (in Chinese)

Sun QH, Lu PY (2019) Bioactive compounds in beetroot and their utilization in food processing industry. China Condiment 44(2):164-167

Tan Y, Cui Y, Li H, Kuang A, Li X, Wei Y, Ji X (2017a) Diversity and composition of rhizospheric soil and root endogenous bacteria in Panax notoginseng during continuous cropping practices. J Basic Microbiol 57(4):337-344

Tan Y, Cui Y, Li H, Kuang A, Li X, Wei Y, Ji X (2017b) Rhizospheric soil and root endogenous fungal diversity and composition in response to continuous Panax notoginseng cropping practices. Microbiol Res 194:10-19

Tang H, Xiao X, Xu Y, Li C, Cheng K, Pan X, Li W (2019) Utilization of carbon sources in the rice rhizosphere and nonrhizosphere soils with different longterm fertilization management. J Basic Microbiol. https://doi.org/10.1002/ jobm.201800736

Tao J, Meng D, Qin C, Liu X, Liang Y, Xiao Y, Liu Z, Gu Y, Li J, Yin H (2018) Integrated network analysis reveals the importance of microbial interactions for maize growth. Appl Microbiol Biotechnol 102(8):3805-3818

van Overbeek L, Van Elsas JD (2008) Effects of plant genotype and growth stage on the structure of bacterial communities associated with potato (Solanum tuberosum L.). FEMS Microbl Ecol 64:283-296

Vives-Peris V, Gómez-Cadenas A, Pérez-Clemente RM (2018) Salt stress alleviation in citrus plants by plant growth-promoting rhizobacteria Pseudomonas putida and Novosphingobium sp. Plant Cell Rep 37(11):1557-1569

Wang F, Chen S, Wang Y, Zhang Y, Hu C, Liu B (2018) Long-term nitrogen fertilization elevates the activity and abundance of nitrifying and denitrifying microbial communities in an upland soil: implications for nitrogen loss from intensive agricultural systems. Front Microbiol 9:2424

Wang P, Marsh EL, Ainsworth EA, Leakey ADB, Sheflin AM, Schachtman DP (2017) Shifts in microbial communities in soil, rhizosphere and roots of two major crop systems under elevated $\mathrm{CO}_{2}$ and $\mathrm{O}_{3}$. Sci Rep 7(1):15019

Wang RD, Yin JZ (2005) Crop cultivation. Higher Education Press, Beijing

Xie XG, Zhang FM, Wang XX, Li XG, Dai CC (2019) Phomopsis liquidambari colonization promotes continuous cropping peanut growth by improving the rhizosphere microenvironment, nutrient uptake and disease incidence. J Sci Food Agric 99(4):1898-1907

Xiong W, Li ZG, Liu HJ, Xue C, Zhang RF, Wu HS, Li R, Shen QR (2015a) The effect of long-term continuous cropping of black pepper on soil bacterial communities as determined by 454 pyrosequencing. PLoS ONE 10(8): e0136946

Xiong W, Zhao Q, Zhao J, Xun W, Li R, Zhang R, Wu H, Shen Q (2015b) Different continuous cropping spans significantly affect microbial community membership and structure in a vanilla-grown soil as revealed by deep pyrosequencing. Microb Ecol 70(1):209-218

Xu L, Zhang Y, Wang L, Chen W, Wei G (2014) Diversity of endophytic bacteria associated with nodules of two indigenous legumes at different altitudes of the Qilian Mountains in China. Syst Appl Microbiol 37(6):457-465

Yadav AN, Sachan SG, Verma P, Tyagi SP, Kaushik R, Saxena AK (2015) Culturable diversity and functional annotation of psychrotrophic bacteria from cold desert of Leh Ladakh (India). World J Microbiol Biotechnol 31(1):95-108

Yang L, Danzberger J, Schöler A, Schröder P, Schloter M, Radl V (2017a) Dominant groups of potentially active bacteria shared by barley seeds become less abundant in root associated microbiome. Front Plant Sci 8:1005
Yang Y, Wang N, Guo X, Zhang Y, Ye B (2017b) Comparative analysis of bacterial community structure in the rhizosphere of maize by high-throughput pyrosequencing. PLoS One 12(5):e0178425

Zachow C, Tilcher R, Berg G (2008) Sugar beet-associated bacterial and fungal communities show a high indigenous antagonistic potential against plant pathogens. Microb Ecol 55(1):119-129.

Zachow C, Müller H, Tilcher R, Berg G (2014) Differences between the rhizosphere microbiome of Beta vulgaris ssp. maritima-ancestor of all beetcrops-and modern sugar beets. Front Microbiol 5:4151.

Zhang $H$, Sun $H$, Yang R et al (2016) Complete genome sequence of a psychotrophic Pseudarthrobacter sulfonivorans strain Ar51 (CGMCC 4.7316), a novel crude oil and multi benzene compounds degradation strain. J Biotechnol 231:81-82

Zhang J, Zhang CW, Yang J, Zhang RJ, Gao JS, Zhao X, Zhao JJ, Zhao DF, Zhang XX (2019) Insights into endophytic bacterial community structures of seeds among various Oryza sativa L. rice genotypes. J Plant Growth Regul 38(1):93-102

Zhao J, Liu J, Liang H, Huang J, Chen Z, Nie Y, Wang C, Wang Y (2018a) Manipulation of the rhizosphere microbial community through application of a new bio-organic fertilizer improves watermelon quality and health. PLoS One 13(2):e0192967

Zhao Q, Xiong W, Xing Y, Sun Y, Lin X, Dong Y (2018b) Long-term coffee monoculture alters soil chemical properties and microbial communities. Sci Rep 8(1):6116

Zhu S, Wang Y, Xu X, Liu T, Wu D, Zheng X, Tang S, Dai Q (2018) Potential use of high-throughput sequencing of soil microbial communities for estimating the adverse effects of continuous cropping on ramie (Boehmeria nivea $\mathrm{L}$. Gaud). PLoS One 13(5):e0197095

\section{Publisher's Note}

Springer Nature remains neutral with regard to jurisdictional claims in published maps and institutional affiliations.

Ready to submit your research? Choose BMC and benefit from:

- fast, convenient online submission

- thorough peer review by experienced researchers in your field

- rapid publication on acceptance

- support for research data, including large and complex data types

- gold Open Access which fosters wider collaboration and increased citations

- maximum visibility for your research: over $100 \mathrm{M}$ website views per year

At BMC, research is always in progress.

Learn more biomedcentral.com/submissions 